\author{
波長変換結晶の熱レンズを考慮した共振器設計による \\ 高出力内部共振器型波長变換固体レーザーの安定化 \\ 小島 哲夫, 安井公治 \\ 三菱電機株式会社 先端技術総合研究所（广 661-0001 兵庫県尼崎市塚口本町 8-1-1）
}

\title{
Stabilization of High-Power Intracavity-Frequency-Doubled Solid-State Laser by Advanced Resonator Design in Consideration of Thermal Lensing of Nonlinear Crystal
}

\author{
Tetsuo KOJIMA and Koji YASUI \\ Advanced Technology $R \&$ D Center, Mitsubishi Electric Corporation \\ 8-1-1 Tsukaguchi-honmachi, Amagasaki, Hyogo 661-0001
}

(Received December 12, 1997)

\begin{abstract}
We have compensated for thermal lensing of nonlinear crystal and Nd:YAG rods by advanced resonator design in a high-power diode-side-pumped intracavity-frequency-doubled CW Nd:YAG laser. The maximum green output power of $27.0 \mathrm{~W}$ was generated with the beam quality of $\mathrm{M}^{2}=7.9$. This value is, to our knowledge, the highest green output power in $\mathrm{CW}$ diode-pumped solid-state lasers. It was found that the green power fluctuation is caused by the unstable zone of the resonator due to the thermal lensing of the nonlinear crystal (KTP). TEM $_{00}$-mode green output power of $16.3 \mathrm{~W}$ was also generated.
\end{abstract}

Key Words: Diode-pumped solid-state laser, Intracavity frequency doubling, Thermal lensing, Nonlinear crystal, Stability zone

1.はじめに

高出力固体グリーンレーザーは, レーザー加工機用の光 源 ${ }^{1}$, 医療用光源 ${ }^{2}$, チタンサファイアレーザー励起光源, お よびレーザーディスプレー用光源3)として期待されてい る. 固体レーザーでは, 高出力グリーン光は, ほとんどが 非線形光学結晶を用いた波長変換により発生される。半 導体レーザー (LD) 励起Qスイッチ固体レーザーでは, ロッ ド型で $106 \mathrm{~W}^{4)}$, スラブ型で $215 \mathrm{~W}^{5)}$ が報告されている。 LD 励起連続発振 (CW) 固体レーザーでは, 側面励起で $\left.10 \mathrm{~W}^{6}\right)$, 端面励起で $8.5 \mathrm{~W}^{7)}$ が報告されている。

内部共振器型波長変換固体レーザーにおいて縦モード 結合によって生じる出力変動“グリーンプロブレム”がBear によって報告されて以来 ${ }^{8)}$, 内部共振器型波長変換固体 レーザーの安定性解析が多くのグループによりなされて きた9-13). 低出力内部共振器型波長変換固体レーザーにお いては,グリーン出力の安定化は縦モード制御, あるいは 偏光モード制御によりなされてきた8-13). しかし, 高出力 内部共振器型波長变換固体レーザーの安定性の解析につ いての報告は少ない14,15).

本論文では, 高効率なLD側面励起構成 16,17$)$ と複レンズ補 償共振器構成 18 を用いた高出力内部共振器型波長変換LD 側面励起固体レーザーの高出力動作について述べる。ま
た, 波長変換結晶の熱レンズのグリーンレーザー安定性へ の影響の解析結果より, 高出力内部共振器型波長变換固体 レーザーの安定化を行った結果について述べる。さらに， 波長変換結晶の熱レンズを考慮した共振器構成によって 行ったTEM $\mathrm{T}_{00}$ モードグリーン光発生についても述べる.

\section{2. 高出カグリーン光発生}

\section{1 実験構成}

高出力内部共振器型波長変換 LD側面励起固体レー ザーの構成をFig.1に示す。本構成においては, 固体レー ザーヘッドを2つ用いた17)。それぞれのレーザーヘッド には, 8つの $20 \mathrm{~W}$ 級LDアレイ,およびフローチューブと拡 散反射集光器に囲まれたNd:YAGロッドが含まれる。こ のレーザーヘッドの均一励起分布と2つの固体レーザー ヘッド間に配置された偏光ローテーターにより, 複レン ズ補償共振器構成となる ${ }^{18)}$. Z型の共振器には, 2つの凹 面エンドミラー, 1 つ平面折り返しミラー,および1つの ハーモニックセパレーターを用いている。内部共振器型 波長変換は, エンドミラーとハーモニックセパレーター 間に配置したKTP $\left(\mathrm{KTiOPO}_{4}\right)$ 結晶によりなされる。“グ リーンプロブレム”を避けるために, $\lambda / 4$ 板をハーモニッ クセパレーターと固体レーザーヘッドの間に配置した。 


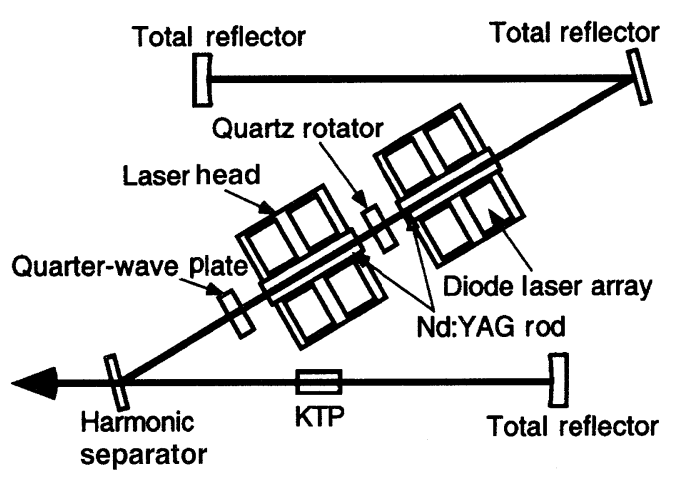

Fig.1 Schematic drawing of the green laser system.

我々は,レーザー出力を熱吸収型パワーメーターにより

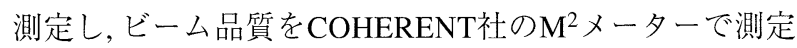
し, 出力時間波形を積分球とPINフォトダイオードにより 測定した。

\section{2 実験結果}

我々は, 2 種類の吸収率の異なるKTP結晶を用いて,グ リーン光発生を行った. Fig.2 に全LDアレイ出力に対する グリーン光出力を示す。長さ $10 \mathrm{~mm}$ の吸収率の低いKTP結 晶(KTP-A)を用いた場合, 全LDアレイ出力 $331.2 \mathrm{~W}$ 時に, グ リーン出力 $27.0 \mathrm{~W} か ゙$ 得られた。この值は, 我々の知るかぎ り, LD励起CW固体グリーンレーザーにおける最高出力で ある.この時, ビーム品質は, $\mathrm{M}^{2}=7.9$ であり, 光効率は $8.2 \%$, 電気一光効率 $2.8 \%$ であた. また, 同構成でKTP結 晶を除いて透過率 $8.0 \%$ 出力ミラーを用いた場合に, 全LD アレイ出力 $331.2 \mathrm{~W}$ 時に基本波出力 $92 \mathrm{~W}$ 得られたことよ り, 基本波からグリーン光への変換効率は $29.3 \%$ となる. 一方, 長さ $15 \mathrm{~mm}$ の吸収率の高いKTP結晶 (KTP-B)を用いた 場合は, 全LDアレイ出力 $331.2 \mathrm{~W}$ 時のグリーン出力は $25.5 \mathrm{~W}$

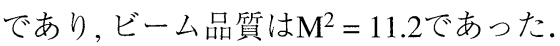

全LDアレイ出力 $331.2 \mathrm{~W}$ 時のグリーン出力時間波形を Fig.3に示す.KTP-Aの場合は周波数数十 kHzオーダーのパ ルス状の出力変動は見られないが, KTP-Bの場合は周波数 数十kHzオーダーのパルス状の出力変動が発生している. 変動周波数に対する出力変動の大きさをFig.4に示す。こ

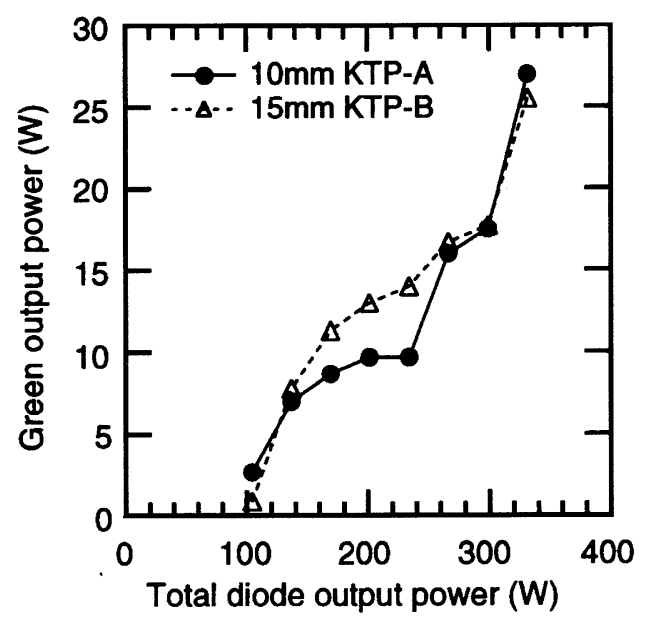

Fig.2 Green output power as a function of the total diode output power.

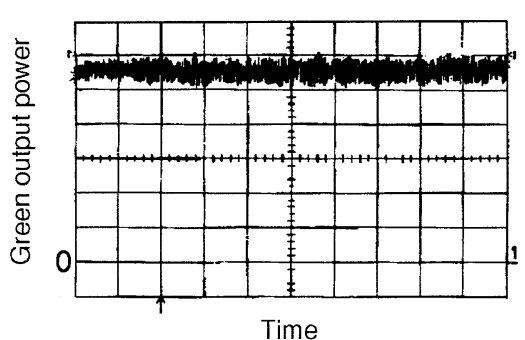

(a)

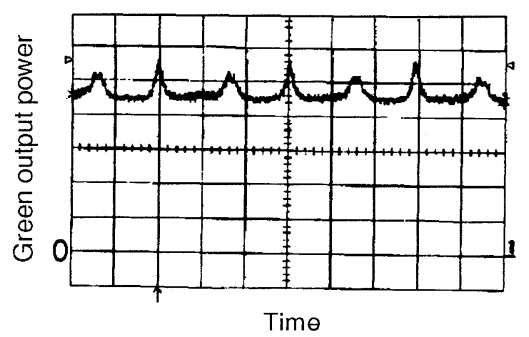

(b)

Fig.3 Time traces of the green output power at the total diode output power of $331.2 \mathrm{~W}$ by use of (a) $10-\mathrm{mm}$ KTP-A and (b) 15-mm KTP-B. Horizontal axis shows $20 \mu \mathrm{s} / \mathrm{div}$.

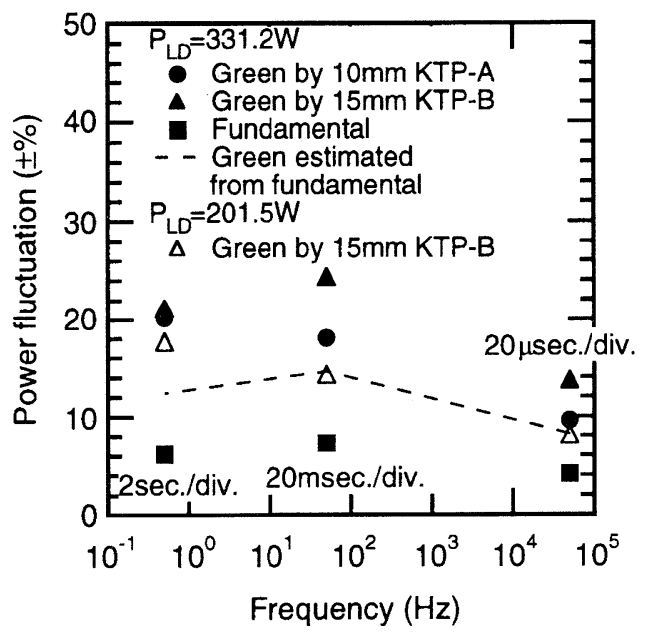

Fig.4 Power fluctuation versus the frequency defined as the inverse of the time scale of the time trace.

こでは, 変動周波数は, 出力時間波形の時間スケールの逆 数と定義している. Fig.4には, 全LDアレイ出力 $331.2 \mathrm{~W}$ 時 の基本波出力変動の大きさ, 基本波出力変動の大きさから 見積もったグリーン出力変動の大きさ, およびKTP-Bを用 いた場合の全LDアレイ出力201.5W時のグリーン出力変動 の大きさを共に示している．KTP-Aの場合, $50 \mathrm{~Hz}$ 以上の周 波数では, グリーン出力変動の大きさは基本波から見積 もったグリーン出力変動の大きさに近い值となってい る.しかし, KTP-Bの場合の $50 \mathrm{~Hz}$ 以上の周波数のグリーン 出力変動の大きさは, 全LDアレイ出力 $201.5 \mathrm{~W}$ 時には, 基本 波から見積もったグリーン出力変動の大きさとほぼ等し いが, 全LDアレイ出力331.2W時には, 基本波から見積もっ たグリーン出力変動の大きさの1.5倍程度大きくなってい る。時間スケール2s/div.のグリーン出力時間波形から, $50 \mathrm{~Hz}$ 以下の周波数のグリーン出力変動は, 高周波の出力変 動により, 基本波から見積もったグリーン出力変動より大 
きくなったと考える。

\section{3. 安定性解析}

我々は, KTP結晶の違いおよびレーザーの動作点の違い によるグリーン出力変動の大きさの違いの原因を調べる ため, KTP結晶の基本波吸収ロスを測定した19)。長さ $15 \mathrm{~mm}$ のKTP-Bの吸収ロスが長さ $10 \mathrm{~mm}$ の KTP-Aの吸収ロスより 10倍大きいことがわかった。

この吸収ロスの違いだけでは,レーザーの動作点の違い によるグリーン出力変動の大きさの違いを説明できない ので,レーザービームの吸収によるKTP結晶の熱レンズを 共振器安定動作範囲の計算に導入した。KTP結晶のグリー ン吸収パワーは基本波吸収パワーの1/10程度のため ${ }^{19)}$, KTP結晶の熱レンズは基本波の吸収によってのみ生じるも のとして, 企LDアレイ出力331.2W時のKTP結晶の熱レンズ 焦点距離を, KTP-Aの場合は約1650mm, KTP-Bの場合は約 $200 \mathrm{~mm}$ と見積もった ${ }^{20)}$. 共振器安定動作範囲の計算は, 光 線行列を用いて行った21)

全LDアレイ出力に対するグリーン出力およびロッド端 に㧍ける共振器ガウスビーム径により表した共振器安定 動作範囲をFig.5に示す. KTP-Aの場合の全LDアレイ出力 331.2WおよびKTP-Bの場合の全LDアレイ出力201.5Wは安 定動作領域の中に入っているが, KTP-Bの場合の全LDアレ イ出力 $331.2 \mathrm{~W}$ は不安定動作領域に近づいている。これよ り,我々は, KTP結晶の違いおよびレーザーの動作点の違い によるグリーン出力変動の大きさの違いと共振器安定動 作領域には関係があると考えた。

\section{4. グリーン出力安定化}

グリーン出力変動の大きさと共振器安定動作領域とに 関係があることを確かめるため, KTP結晶の熱レンズを考 慮して,長さ $15 \mathrm{~mm}$ のTP-Bに対する共振器を再設計した。 再設計した共振器 (改善型共振器)では, 共振器長を変化さ せることにより, 全LDアレイ出力 $331.2 \mathrm{~W} の$ 動作点を安定

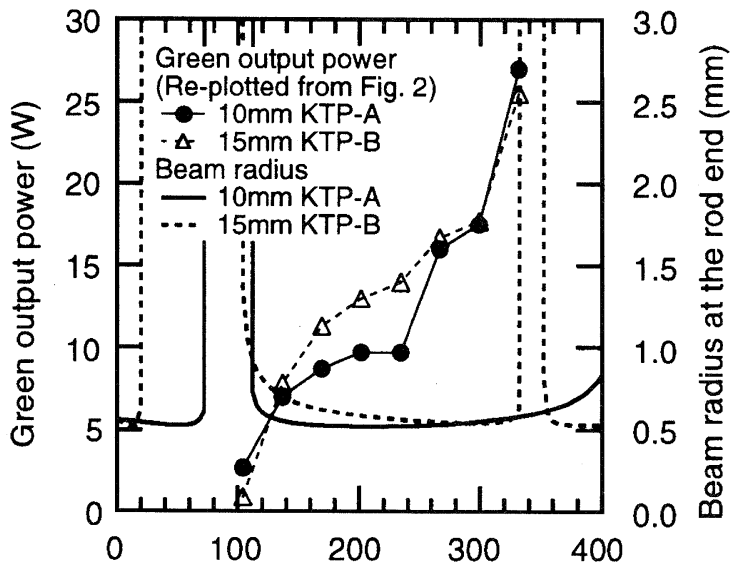

Total diode output power (W)

Fig.5 Green output power and calculated stability zone as a function of the total diode output power.

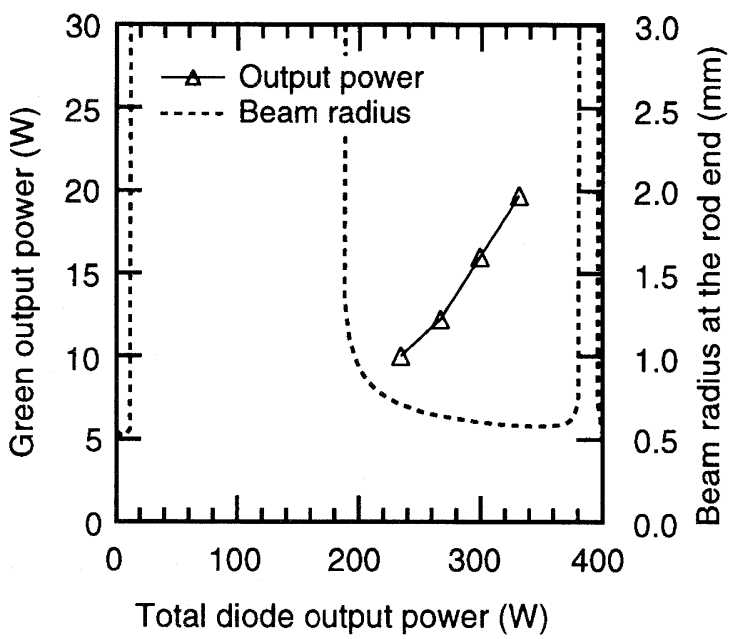

Fig.6 Green output power and the calculated stability zone as a function of the total diode output power in the case of the improved resonator with the 15-mm KTPB.

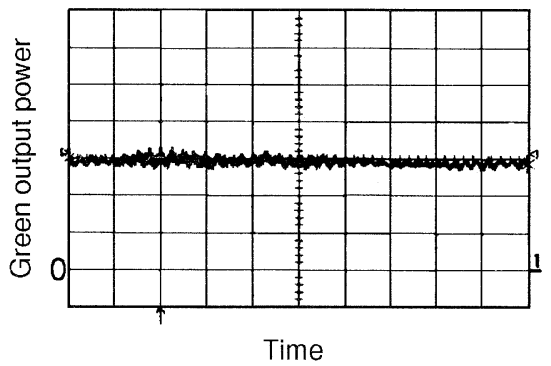

Fig.7 Time traces of the green output power at the total diode output power of $331.2 \mathrm{~W}$ in the case of the improved resonator with 15-mm KTP-B. Horizontal axis shows $20 \mathrm{~ms} / \mathrm{div}$.

動作領域内に入るようにしている。長さ $15 \mathrm{~mm}$ のKTP-Bを 用いた改善型共振器における全LDアレイ出力に対するグ リーン出力および共振器安定動作範囲をFig.6に示す。全 LDアレイ出力 $331.2 \mathrm{~W} か ゙$ 安定動作領域内に入っていること

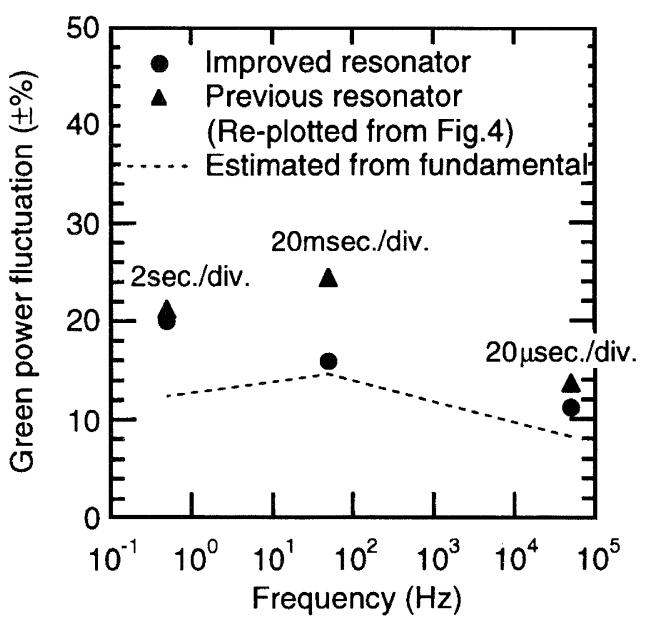

Fig.8 Green power fluctuation versus the frequency defined as the inverse of the time scale of the time trace in the case of the improved resonator with the $15-\mathrm{mm}$ KTP-B at the total diode output power of $331.2 \mathrm{~W}$. 
がわかる. 全LDアレイ出力 $331.2 \mathrm{~W}$ 時のグリーン出力時間 波形を示すFig.7より, 共振器安定動作領域内でレーザーを 動作させることにより, パルス状の出力変動は発生しない ことがわかる. 出力時間波形の時間スケールの逆数と定 義した变動周波数に対する全LDアレイ出力 $331.2 \mathrm{~W}$ 時のグ リーン出力変動の大きさをFig.8に示す。ここでは, 長さ $15 \mathrm{~mm}$ のKTP-Bを用いた改善前の共振器における出力変動 の大きさおよび基本波出力変動の大きさから見積もった グリーン出力変動の大きさを共に示している. $50 \mathrm{~Hz}$ 以上 の周波数においては, 改善型共振器におけるグリーン出力 変動の大きさは, 改善前の共振器におけるグリーン出力変 動の大きさより小さくなり, 基本波から見積もったグリー ン出力変動の大きさとほぼ等しくなっている. 吸収率の 大きいKTP-Bを用いても, 共振器安定動作領域内でレー ザーを動作させることにより,グリーン出力を安定化でき ることがわかった。したがって, 我々は, 大きなグリーン パワー出力変動はKTP結晶の熱レンズによって生じる共振 器不安定動作領域によって引き起こされると考える.

また, 我々は, 高吸収率のKTP-Bの温度分布が低吸収率の KTP-Aの温度分布より大きいため, KTP-Bの変換効率が下 がり, 長さ $15 \mathrm{~mm}$ のTP-Bを用いた場合のグリーン出力が長 さ10mmのKTP-Aを用いた場合のグリーン出力とほぼ等し くなったと推測する.

\section{5. $\mathrm{TEM}_{00}$ モードグリーン光発生}

KTP結晶の熱レンズを考慮した共振器設計方法により, $\mathrm{TEM}_{00}$ モード動作可能な共振器を設計した. $\mathrm{TEM}_{00}$ モード 動作のため, 凹面エンドミラーを凸面エンドミラーに変更 し, 共振器長を延長することにより, ロッド端面における 共振器ガウスビーム径を拡大した。長さ $10 \mathrm{~mm}$ のKTP-Aを 用いた場合の全LDアレイ出力に対するグリーン出力, ビー ム品質 $\mathrm{M}^{2}$, および共振器安定動作範囲をFig.9に示す。全 $\mathrm{LD}$ アレイ出力 $315.0 \mathrm{~W}$ 時に $\mathrm{TEM}_{00}$ モードグリーン出力 $16.3 \mathrm{~W}$ 得た。 ビーム品質は, $\mathrm{M}^{2}=1.2$ であった. 光効率は

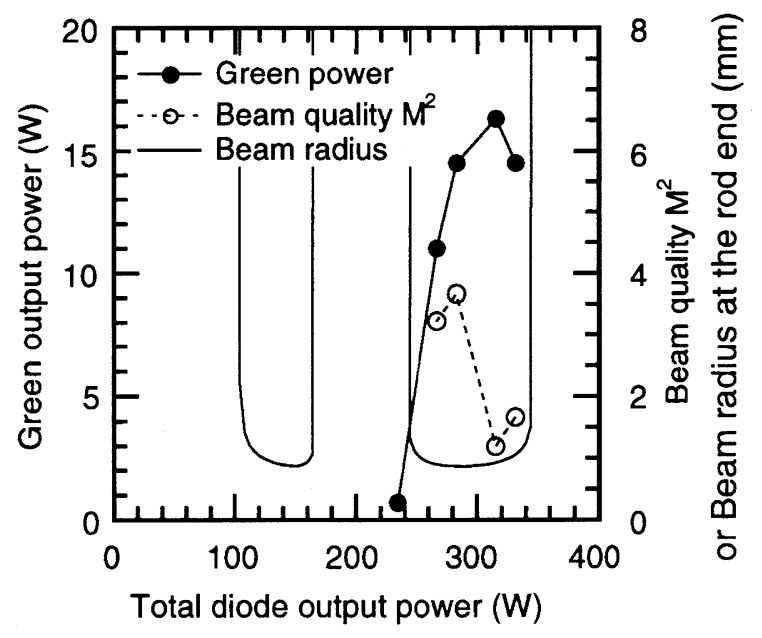

Fig.9 Green output power, beam quality, and the calculated stability zone as a function of the total diode output power in the case of the $\mathrm{TEM}_{00}$-mode resonator with the 10-mm KTP-A.

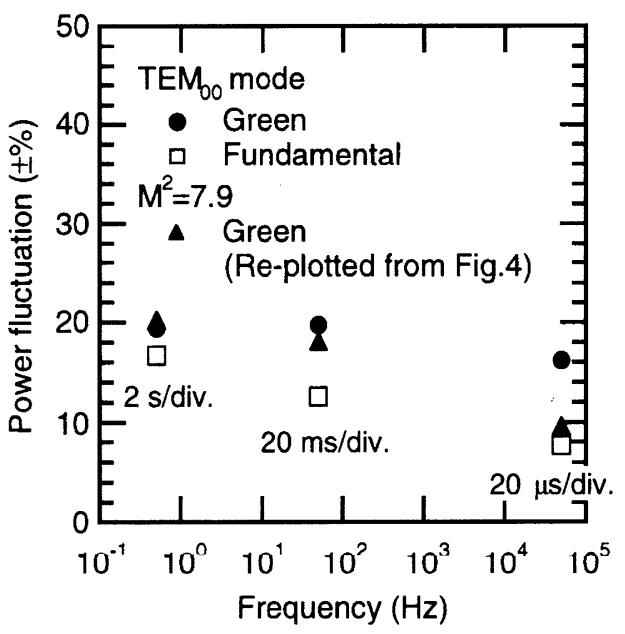

Fig.10 $\mathrm{TEM}_{00}$-mode green power fluctuation versus the frequency defined as the inverse of the time scale of the time trace.

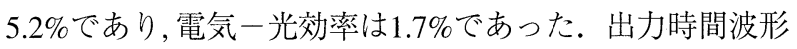
の時間スケールの逆数と定義した変動周波数に対する $\mathrm{TEM}_{00}$ モードグリーン出力変動の大きさ, $\mathrm{TEM}_{00}$ モード基 本波出力変動の大きさ, およびビーム品質 $\mathrm{M}^{2}=7.9$ 時のグ リーン出力変動の大きさをFig.10に示す. 周波数 $50 \mathrm{~Hz}$ 以下 においては, $\mathrm{TEM}_{00}$ モードグリーン光はビーム品質 $\mathrm{M}^{2}=7.9$ 時のグリーン光と同程度に安定化できた。周波数 $50 \mathrm{kHz}$ おける $\mathrm{TEM}_{00}$ モードグリーン出力変動の大きさはビーム品 質 $\mathrm{M}^{2}=7.9$ 時のグリーン出力変動の大きさより大きくなっ ているが,これは $\mathrm{TEM}_{00}$ モード時の基本波出力変動が大き くなったことによる. $\mathrm{TEM}_{00}$ モード時の基本波出力変動が 大きくなったのは, 不安定動作領域に近い動作点で動作し ていることが原因であり，安定動作領域の中央付近で $\mathrm{TEM}_{00}$ モード動作できるように共振器を変更すれば, さら に安定な $\mathrm{TEM}_{00}$ モードグリーン出力が得られると考える.

\section{6. まとめ}

我々は, 内部共振器型波長变換LD側面励起CW Nd:YAG レーザーの高出力動作を行い, 波長変換結晶の熱レンズの グリーンレーザー安定性への影響の解析結果より, 高出力 内部共振器型波長変換固体レーザーの安定化を行った。 さらに, 波長変換結晶の熱レンズを考慮した共振器構成に よって $\mathrm{TEM}_{00}$ モードグリーン光発生も行った。

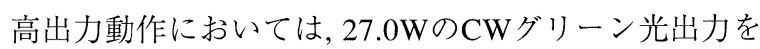
ビーム品質 $\mathrm{M}^{2}=7.9$ で得た。この值は, 我々の知るかぎり, LD励起CW固体グリーンレーザーにおける最高出力であ 万.

高出力内部共振器型波長変換固体レーザーの安定性解 析においては, KTP結晶の熱レンズによって生じる共振器 不安定動作領域にレーザーの動作点が近づくことがグ リーンレーザーの大出力変動の原因であることがわかっ た. KTP結晶の熱レンズを考慮して共振器を設計し, 共振 器安定動作領域内で動作させることにより,グリーンレー ザーの安定化を行った. 高出力内部共振器型波長变換固 
体レーザーにおいては, 波長変換結晶の熱レンズを考慮し て共振器を設計する必要がある。

$\mathrm{TEM}_{00}$ モード動作においては, KTP結晶の熱レンズを考 慮した共振器を用いることにより, 16.3WのCWグリーン光 出力をビーム品質 $\mathrm{M}^{2}=1.2$ で得た. 今後, さらなる高出力 化・高安定化を目指したい.

\section{謝 辞}

本研究を理解し, 御支援をいただいた吉沢 憲治氏, 田中 正明氏, 八木 重典氏, 並びに本研究に対する御協力, 有益 な議論をいただいた藤川周一氏に深く感謝いたします。

\section{参考文献}

1) J. Golden: LASER FOCUS WORLD (1992, June) p.75.

2) M. V. Ortiz, J. H. Fair, and D. J. Kuizenga: OSA Proceedings on Advanced Solid-State Lasers, 1992 (Optical Society of America, Washington, D. C., 1992) p.361.

3) W. E. Glenn: OSA Trends in Optics, and Photonics Vol. 10, Advanced Solid State Lasers, 1997 (Optical Society of America, Washington, D. C., 1997) p.38.

4) B. J. Le Garrec, G. J. Razé, P. Y. Thro, and M. Gilbert: Proc. LEOS '96 9th annual meeting, vol. 2 (IEEE, Piscataway, 1996) p.222.

5) W. T. Lotshaw, M. J. Kukla, A. L. Oritiz Jr., P. R. Staver, J. R. Unternahrer, R. Burnham, and G. Moule: Postdeadline Papers of Conf. Lasers and Electro-Optics '97 (Optical Society of America, Washington, D. C., 1997) paper CPD33.
6) D. Golla, S. Knoke, W. Schöne, M. Bode, A. Tünnermann, and H. Welling: Nonlinear Frequency Generation and Conversion, Proc. SPIE vol. 2700 (1996) p.314.

7) M. D. Selker, T. J. Johnston, G. Frangineas, J. L. Nightingale, and D. K. Negus: Postdeadline Papers of Conf. Lasers and Electro-Optics '96 (Optical Society of America, Washington, D. C., 1996) paper CPD21.

8) T. Baer: J. Opt. Soc. Am. B 3 (1986) 1175.

9) D. W. Anthon, D. L. Sipes, T. J. Pier, and M. R. Ressl: IEEE J. Quantum Electron. QE-28 (1992) 1148.

10) M. Oka and S. Kubota: Opt. Lett. 13 (1988) 805

11) G. E. James, E. M. Harrel II, C. Bracikowski, K. Wiesenfeld, and R. Roy: Opt, Lett. 15 (1990) 1141.

12) X-G Wu and P. Mandel: J. Opt. Soc. Am. B 4 (1987) 1870.

13) H. Nagai, M. Kume, I. Ohta, H. Shimizu, and M. Kazumura: IEEE J. Quantum Electron. QE-28 (1992) 1164.

14) V. Magni, G. Cerullo, S. De Silvestri, O. Svelto, L. J. Qian, and M. Danailov: Opt. Lett. 18 (1993) pp.2111.

15) W. L. Nighan, Jr. and J. Colc: Postdeadline Papers of Advanced Solid State Lasers, 1996 (Optical Society of America, Washington, D. C., 1996) paper PD4.

16) T. Kojima and K. Yasui: Post Deadline Papers of CLEO/Pacific Rim, 1995 (IEEE, Piscataway, 1995) paper PD2.2.

17) S, Fujikawa, T. Kojima, and K. Yasui: IEEE J. Selected Topics in Quantum Electron. 3 (1997) p.40.

18) K. Yasui: Appl. Opt. 35 (1996) p.2566.

19) T. Kojima and K. Yasui: OSA Proceedings on Advanced Solid-State Lasers, vol. 24 (Optical Society of America, Washington, D. C., 1995) p.80.

20) W. Koechner: Solid-State Laser Engineering, 4th ed. (SpringerVerlag, Berlin, 1995) p.400.

21) A. E. Siegman: Lasers (University Science Books, Mill Valley, 1986) p.581. 